\title{
The Role of Dietary Polyphenols on Adult Hippocampal Neurogenesis: Molecular Mechanisms and Behavioural Effects on Depression and Anxiety
}

\author{
Gisele Pereira Dias, ${ }^{1,2,3}$ Nicole Cavegn, ${ }^{1}$ Alina Nix ${ }^{1}$ Mário Cesar do Nascimento Bevilaqua, ${ }^{2}$ \\ Doris Stangl, ${ }^{1}$ Muhammad Syahrul Anwar Zainuddin, ${ }^{1}$ Antonio Egidio Nardi, ${ }^{3}$ \\ Patricia Franca Gardino, ${ }^{2}$ and Sandrine Thuret $^{1}$ \\ ${ }^{1}$ Institute of Psychiatry, King's College London, 125 Coldharbour Lane, London SE5 9NU, UK \\ ${ }^{2}$ Program of Neurobiology, Laboratory of Neurobiology of the Retina, Institute of Biophysics, Universidade Federal do Rio de Janeiro \\ (UFRJ), Bloco C, sala 31, Avenida Carlos Chagas Filho 373, 21941-902 Rio de Janeiro, RJ, Brazil \\ ${ }^{3}$ Laboratory of Panic \& Respiration, Institute of Psychiatry, Universidade Federal do Rio de Janeiro (UFRJ), Avenida Venceslau Brás, \\ 71 Fundos, 22290-140 Rio de Janeiro, RJ, Brazil
}

Correspondence should be addressed to Sandrine Thuret, sandrine.1.thuret@kcl.ac.uk

Received 10 February 2012; Revised 10 April 2012; Accepted 17 April 2012

Academic Editor: Tullia Maraldi

Copyright ( $) 2012$ Gisele Pereira Dias et al. This is an open access article distributed under the Creative Commons Attribution License, which permits unrestricted use, distribution, and reproduction in any medium, provided the original work is properly cited.

\begin{abstract}
Although it has been long believed that new neurons were only generated during development, there is now growing evidence indicating that at least two regions in the brain are capable of continuously generating functional neurons: the subventricular zone and the dentate gyrus of the hippocampus. Adult hippocampal neurogenesis (AHN) is a widely observed phenomenon verified in different adult mammalian species including humans. Factors such as environmental enrichment, voluntary exercise, and diet have been linked to increased levels of AHN. Conversely, aging, stress, anxiety and depression have been suggested to hinder it. However, the mechanisms underlying these effects are still unclear and yet to be determined. In this paper, we discuss some recent findings addressing the effects of different dietary polyphenols on hippocampal cell proliferation and differentiation, models of anxiety, and depression as well as some proposed molecular mechanisms underlying those effects with particular focus on those related to AHN. As a whole, dietary polyphenols seem to exert positive effects on anxiety and depression, possibly in part via regulation of AHN. Studies on the effects of dietary polyphenols on behaviour and AHN may play an important role in the approach to use diet as part of the therapeutic interventions for mental-health-related conditions.
\end{abstract}

\section{Introduction}

A long-standing dogma in the brain sciences stated that new neurons were only generated during development. However, in the mid-1900s new evidence indicated the need for a change in this doctrine, as an unknown capacity in the adult mammalian brain started to be unraveled: adult neurogenesis.

Two regions in the adult mammalian brain, including human [1], can be pointed as neurogenic sites [2]: the subventricular zone (SVZ), located along the sides of the lateral ventricles, and the subgranular zone (SGZ) of the dentate gyrus (DG) in the hippocampus.
The new neurons generated in the SVZ migrate through a precise route, the rostral migratory stream (RMS), and integrate into the olfactory bulb, where they continuously replace local neurons [3]. In the DG, new neurons are generated from two types of progenitors or precursors located in the SGZ [4]: type 1 hippocampal progenitors, which extend a radial process across the granular layer, ramifying in the inner molecular layer, and type 2 cells, which are hippocampal progenitors with short processes (Figure 1, also showing the 3 types of progenitor cells lying adjacent to the ependymal cell layer in the SVZ: type B cells, which are GFAP positive; type $C$ transit amplifying cells; type $A$, which are migrating neuroblasts) [4]. 


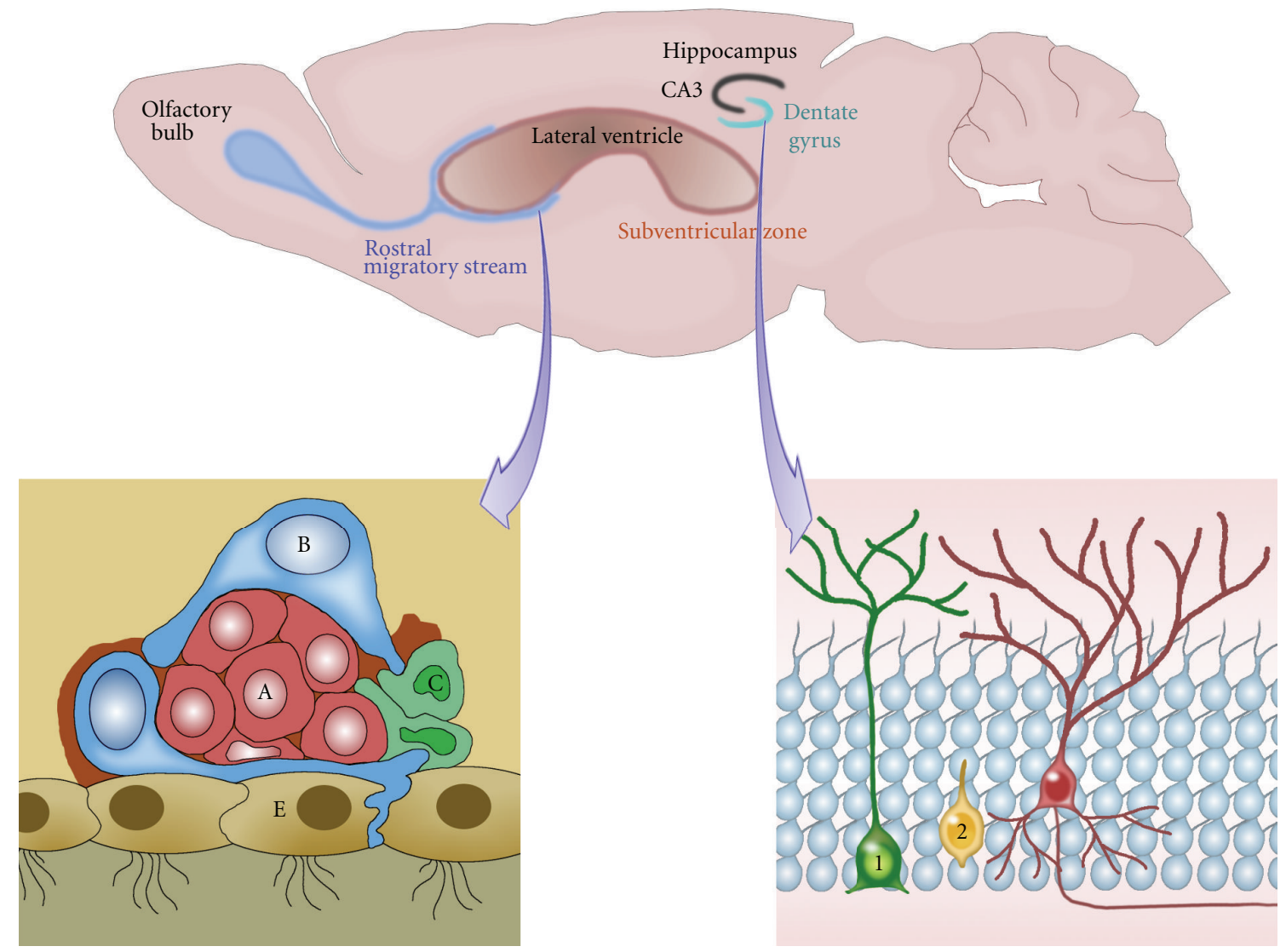

FIGURE 1: Adult neurogenesis in the mammalian brain. The figure illustrates the two well-known neurogenic sites in the brain: the subventricular zone (SVZ) and the dentate gyrus of the hippocampus (DG). Three types of progenitor cells are found lying adjacent to the ependymal cell layer (E) in the SVZ: A subset of relatively quiescent GFAP+ radial cells (type B cells) in the SVZ has the potential to serve as adult NSCs and generate rapidly dividing, transit-amplifying nonradial NSCs (type C cells), which in turn give rise to neuroblasts (type A cells) that migrate through the rostral migratory stream toward the olfactory bulb. In the adult SGZ, a population of GFAP+ Sox $2+$ radial cells corresponds to quiescent NSCs (type 1 cells). They coexist with actively proliferating, GFAP+ Sox $2+$ nonradial NSCs (type 2 cells) that generate both astrocytes and neuroblasts. Neuroblasts then migrate into the granule cell layer and mature into neurons (red cell).

The new neurons generated in the adult hippocampus, specifically in the SGZ of the DG, migrate to the inner layer of the granular zone, where they send/receive synaptic contacts [5].

Adult neurogenesis is a widely preserved phenomenon, being verified in different mammalian species such as mice, rats, guinea-pigs, monkeys, and humans [1, 6-12]. In both mentioned neurogenic sites, adult neurogenesis follows defined stages, identified as proliferation, cell fate determination, migration, and synaptic integration [5]. Many factors can impact the regulation of these different steps, possibly via the influence of factors released from vasculature $[13,14]$ and complex cell-cell interactions, between progenitor cells and other progenitors, astrocytes, and local/distal neurons [4].

Some environmental factors have been shown to influence adult hippocampal neurogenesis (AHN), such as voluntary exercise, enriched environment, and caloric restriction that increase the rates of AHN [15-17], whereas stressful conditions like aging or stress itself have a decreasing influence $[8,18]$.
Stress is one of the most potent negative modulators of hippocampal neurogenesis, as demonstrated in several species of mammals [19]. This effect has been demonstrated by different paradigms, such as exposure to predator odour [20], resident-intruder model of stress [8], psychosocial stress [21], inescapable shock [22], and others (reviewed in [23]). However, the mechanisms involved in this deleterious effect have not yet been totally clarified. There is evidence of a role for hormones and cytokines released during stress in modulating AHN. Indeed, AHN is very sensitive to the increase in corticoid levels [19], with these hormones negatively regulating it. It is also known that the hippocampus plays a role on the regulation of endocrine functions, possibly promoting a negative regulation of the hypothalamuspituitary-adrenal (HPA) axis [24]. This involvement of the hippocampus is evidenced by the high concentration of glucocorticoid and mineralocorticoid receptors in this brain structure (reviewed in [25]). However, there is also evidence of a role for the newly generated neurons buffering the stress response. Indeed, a recent study has shown that the ablation of AHN led to a modulation of glucocorticoid levels after 
moderate stress, with a sustained increase in the levels of these hormones even after a significant period following the stressful event [26]. This reinforces the modulating role of the hippocampus on the HPA axis through both AHN and the more established negative feedback via glucocorticoid receptors. This same study has suggested a relation between neurogenesis and the aetiology of depression. As stated, it has been proposed that depressed individuals have reduced hippocampal volume $[27,28]$. In addition, there is increasing evidence from animal research that antidepressants might exert a proneurogenic effect in the hippocampus [29], and the ablation of neurogenesis has led to depressive behaviour in animals tested in the forced swimming test (FST) and in the sucrose preference test (SPT) $[26,30]$.

The role of AHN is still intensely debated. While several contradictory findings emerge when analyzing the literature, evidence in favour of a relevant role of adult-born neurons in hippocampus-dependent learning is compelling; spatial and associative memory is impaired in rodents under conditions that decrease AHN, whereas hippocampus-dependent learning tasks are solved better under conditions that increase AHN (reviewed in [31]).

AHN is also said to play a role in different neurodegenerative, neurological, and psychiatric disorders such as Alzheimer's and Parkinson's disease, anxiety, and depression. With regard to the latter, a small reduction of hippocampal volume has been found in human patients suffering from depression, suggesting an involvement of the hippocampus in mood disorders [27, 28]. Reduced AHN in different animal models of depression supports this observation as well as the ability of antidepressants to restore it $[22,28]$. However, data from different studies are still controversial and the specific features that characterise the involvement of AHN in depression and anxiety are not absolutely clear. On the one hand, decreased AHN does not necessarily induce depressive behaviour in laboratory rodents [30, 32] and on the other hand, minimally normal levels of AHN have been shown to be necessary for the successful effect of some antidepressants [30, 33], and for buffering depressive behaviour [26].

Several studies during the last 5 years suggest that changes in diet can have a positive influence on neurogenesis, learning, and memory as well as cognition and mood (reviewed in [34]). As mentioned, laboratory rodents that were fed under calorically restricted conditions had a higher amount of AHN than ad libitum fed fellows, a process most likely regulated via the brain-derived neurotrophic factor (BDNF) [17]. Other positive effects on brain function were achieved by omega-3 fatty acids and vitamins, as well as by polyphenolic components of grapes, blueberries, cocoa, or teas (reviewed in $[35,36])$. Polyphenolic compounds are phytochemicals known for their biological antioxidative, neuroprotective, and cognitive properties. For instance, it has been shown that different polyphenols can increase synaptic plasticity in the context of AHN [37-40] and also promote hippocampal long-term potentiation [41]. In addition, it has been verified that polyphenols can enhance learning and memory $[42,43]$ and reduce the risk of developing agerelated neurodegenerative diseases $[44,45]$, possibly via a decrease in reactive oxygen species (ROS) production and inflammation in models of aging $[46,47]$.

Besides antidepressant drugs, different polyphenolic compounds such as catechins (flavanols/flavonoid from green tea), curcumin (nonflavonoid from tumeric/Curcuma longa), and resveratrol (stilbenoid produced naturally by several plants when under attack/found high in red grape skin) have been observed to have antidepresssant-like effects in rodents and human [48-52]. This suggests that polyphenols could be key compounds for the improvement of psychiatric disorders like depression or anxiety.

The facts that polyphenols have been shown to be helpful compounds against depression and that they can increase AHN suggest that these molecules might affect mood, and not only cognition, via AHN. In this way, this paper aims to address this hypothesis, discussing the effects of dietary polyphenols on mental health, particularly on depression and anxiety, and the possible molecular mechanisms underlying these effects via AHN regulation.

\section{Polyphenols and AHN}

2.1. Effects of Polyphenols on AHN. Many of the studies about the impact of polyphenols on the hippocampus have relied on the antioxidant properties of these molecules and their neuroprotective effect in different models of brain injury [53-61] (see Table 1 for details), with the majority of them not having addressed AHN. However, the emerging evidence of hippocampal plasticity offered by the mechanisms underlying AHN has made this phenomenon a promising target for pharmacological, environmental, and nutraceutical interventions, such as polyphenolic diet, raising the need for studies focusing on how these factors could impact the ability of the adult hippocampus to generate new functional neurons.

A positive role of a diet enriched in polyphenols and polyunsaturated fatty acids (LMN diet) on adult mice neurogenesis has been shown [37]. Following 40 days of LMN diet, different markers of AHN have been found to be increased in comparison to mice under control diet, such as the number of newly generated cells in the SGZ (as well as in the SVZ), with significantly more cells expressing the neuroblast marker doublecortin, suggesting that the LMN diet had an effect on neuronal populations. Indeed, the rise in neuronal differentiation was confirmed by the increased colocalization of the cell proliferation marker 5-bromo2 -deoxyuridine (BrdU) and $\mathrm{NeuN}$-expressed in mature neurons - in neurons of the granule layer of animals fed with the polyphenolic/fatty acid-enriched diet. Although more is yet to be specifically clarified, one of the possible mechanisms suggested for the increase in AHN by this special diet could be the induction of hippocampal plasticity factors such as insulin-like growth factor-1 (IGF-1) and its receptor (IGF-1R), as previously shown by short-term blueberry supplementation in rats [62]. In addition, the neurogenic potential of the LMN diet has also been suggested in a recent study that showed it to be capable of increasing to $70 \%$ the rate of cell proliferation in the SVZ of a mouse model of Alzheimer's disease [54]. However, since 


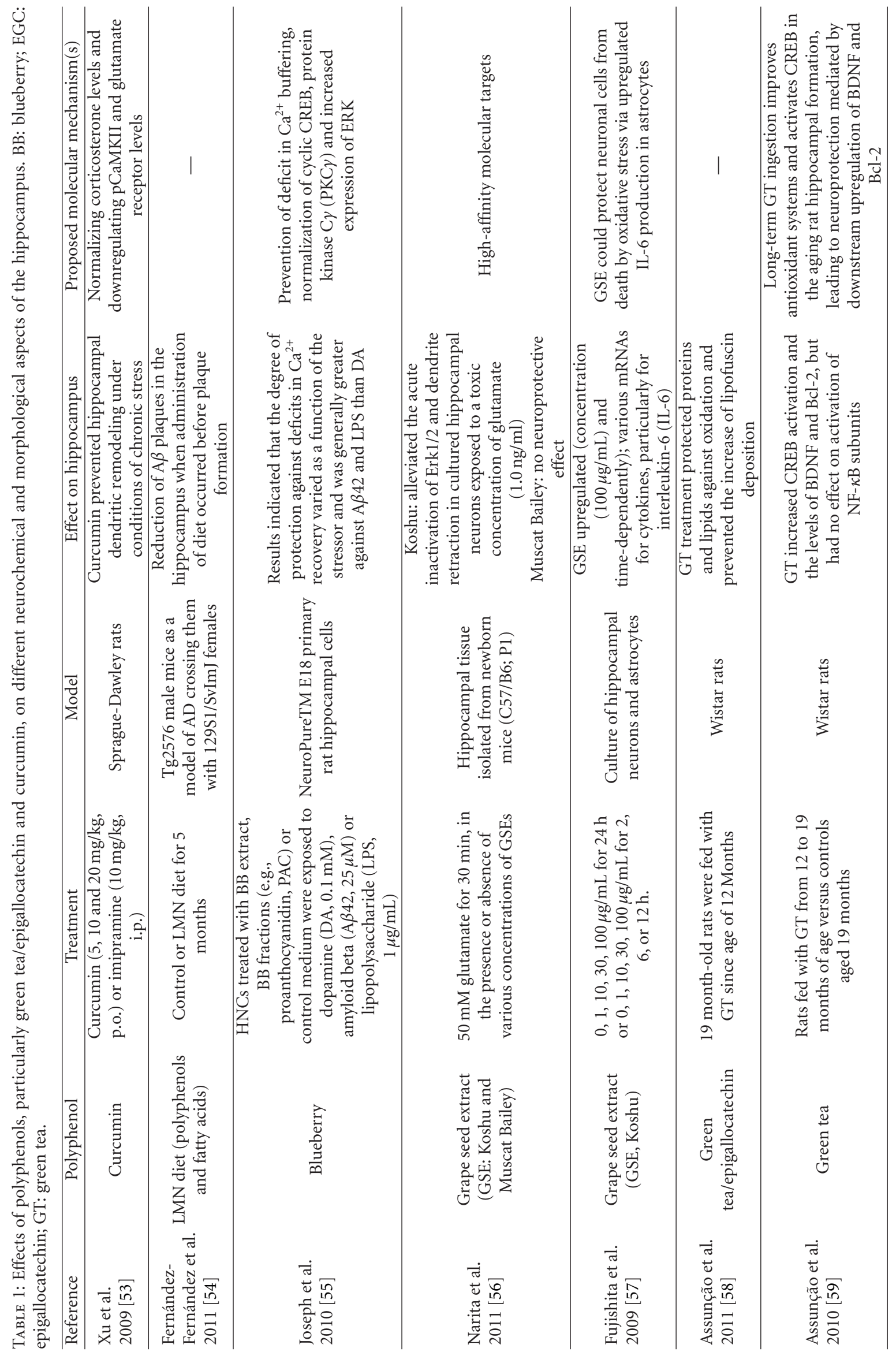




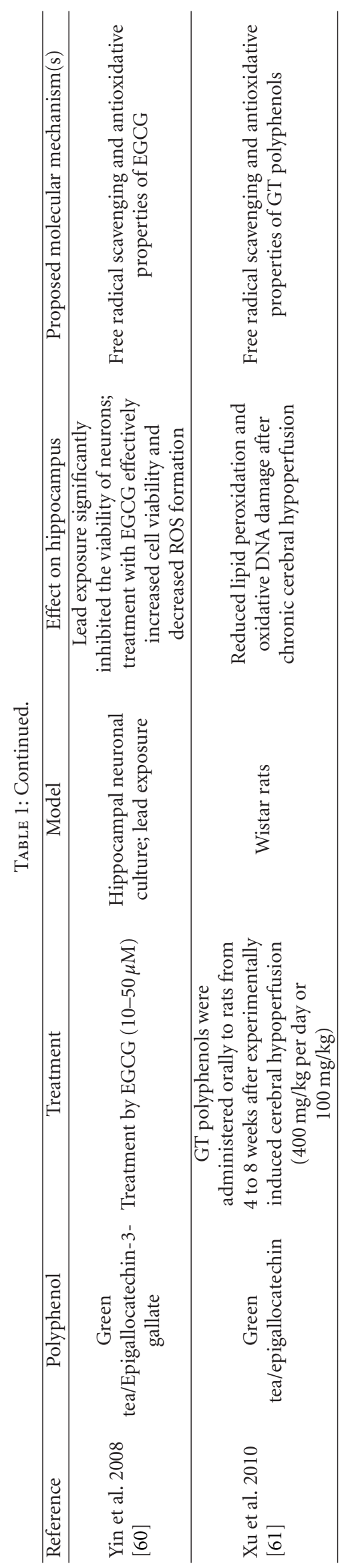


a fatty-acid-(F-A) exclusive diet has not been used, there is no conclusive evidence that the effects found are due only to polyphenols. In this sense, the contribution of FA or a synergistic effect of polyphenols and FA should be considered.

This positive effect of polyphenols on hippocampal neurogenesis has also been demonstrated in vitro, with low concentrations of curcumin stimulating cell differentiation in cultures of multipotent mouse neural progenitor cells. A similar effect has been demonstrated in vivo, with increased AHN in mice administered with this polyphenol [38] (see Section 3.2.2 for further discussion on the effects of curcumin on mental health and possible molecular mechanisms underlying it).

In addition to curcumin, the interaction between polyphenol and chronic stress has also been found with the administration of flavonoids. In this sense, administration of flavonoids extracted from Chinese herb Xiaobuxin-Tang (XBXT-2) significantly increased hippocampal neurogenesis in chronically stressed rats [39]. Additionally, XBXT-2 treatment reversed the stress-induced decrease of hippocampal BDNF and phosphorylated cyclic AMP-response element DNA-binding protein (pCREB) (Ser133) expression, two important factors closely related to hippocampal neurogenesis. Interestingly, as occurred with curcumin, the positive effects of these flavonoids were comparable to those achieved with imipramine treatment.

Dietary polyphenols are thought to be the most abundant antioxidants in foods and beverages [63], with particular potential to inhibit neuroinflammation (reviewed in [64]). Thus, with special regard to inflammation, oxidative stress and microglial activation-all factors known to decrease cell proliferation and neuroplasticity-it has been shown that neural progenitor cell proliferation and spatial memory performance are increased, with decreased microglial activation, in aged rats submitted to 4 weeks of treatment with NT-020 - a natural diet based on the combination of polyphenols from blueberry and green tea, as well as antioxidant and anti-inflammatory amino acids like carnosine [65]. It is well established that one of the physiological markers of aging is the increase in circulating factors such as cytokines and chemokines, known to increase proinflammatory factors that exert a negative effect on the progenitor cell pools. The authors then suggest that the positive influence of the NT-020 diet on health promotion could occur via the promotion of proliferation and survival of neurons, as well as by anti-inflammatory actions that influence the stem cell niche of the aged brain [65].

Table 2 summarises the studies discussed before, on the effects of polyphenols on hippocampal cell proliferation and differentiation.

\section{Polyphenols and Mental Health}

3.1. Effects of Dietary Polyphenols on Depression and Anxiety: Behavioural Aspects and Proposed Mechanisms of Action. There is a growing body of data from animal and human studies supporting the role of a variety of dietary polyphenols in affecting behaviour and mood through anxiolytic and antidepressant-like properties (see Table 3). The varied mechanisms proposed for the effects of polyphenols on mental health and the mounting evidence for the role of each are suggestive of the complexity of the diverse interactions influencing mood and behaviour. Thus the multiple cellular and molecular mechanisms resulting in antidepressant-like or anxiolytic effects of a particular polyphenol can reveal potential targets at the level of the individual pathways which may collectively contribute to a common behavioural phenotype in the context of the etiologies of anxiety and depressive disorders and expand our understanding of interactions of these pathways.

The proposed mechanisms for polyphenol effects on mental health are not limited to their well-established antioxidant effects and are as varied as the different polyphenols themselves and the sources in which they are found. Chlorogenic acid is a common dietary polyphenol found in fruits such as plums, apples, and cherries and beverages such as tea and coffee which has been shown to have anxiolytic effects in animal studies $[67,76]$. Chlorogenic acid has been demonstrated to have a number of effects on a cellular level, leading to several proposed mechanisms for its overall anxiolytic effects. In one study, the anxiolytic effect of chlorogenic acid was blocked in vivo by the benzodiazepine receptor antagonist flumazenil, suggesting that anxiety is reduced by activation of the benzodiazepine receptor [67]. In vitro, chlorogenic acid protected granulocytes from oxidative stress, which is another proposed important contributor to anxiety [67]. It has also been found to have neurotrophic effects in vitro that stimulate neuronal differentiation and neurite growth, supporting neuroplasticity, which also may contribute to its anxiolytic effects [66].

Other polyphenols have been shown to exert anxiolytic effects with proposed mechanisms that overlap those of chlorogenic acid. Like chlorogenic acid, the green tea polyphenol epigallocatechin-3-gallate (EGCG) has also been shown to have anxiolytic properties in animal studies with comparable results to a benzodiazepine anxiolytic drug [68]. In vitro work with cultured hippocampal neurons confirmed the specific modulation of the GABA-A receptor benzodiazepine site by EGCG [68].

However, other studies suggest that different pathways might contribute to the anxiolytic effects of other polyphenols. Anthocyanin polyphenols from Vaccinium berries (a genus which includes highbush blueberries, rabbiteye blueberries, and bilberries) also show anxiolytic effects in animal studies but in vitro studies have elucidated several different mechanisms which may be responsible for the anxiolytic property of this class of polyphenols $[69,77,78]$. The antioxidant properties of anthocyanins from rabbiteye blueberries were shown to reduce oxidative damage to neural DNA and this antioxidant neural protection was proposed as a mechanism for the anxiolytic property of berries [69]. Berry anthocyanins also inhibit monoamine oxidases (MOAs), providing neuroprotective effects and counteracting the MOA activity of lowering neural levels of serotonin, noradrenaline, and dopamine whose low levels have been implicated in the etiology of anxiety disorders [77]. Blueberry polyphenols also have anti-inflammatory 


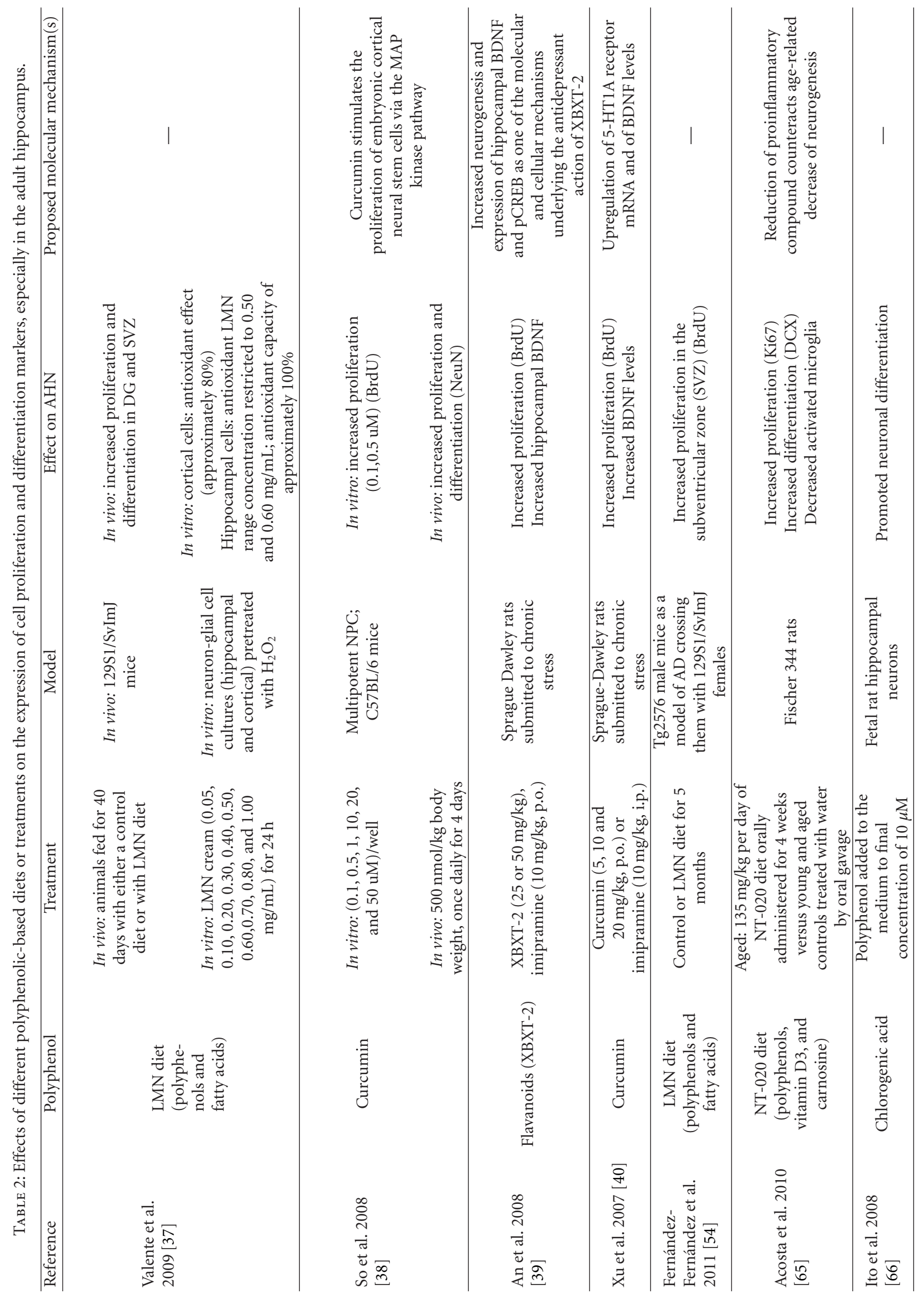




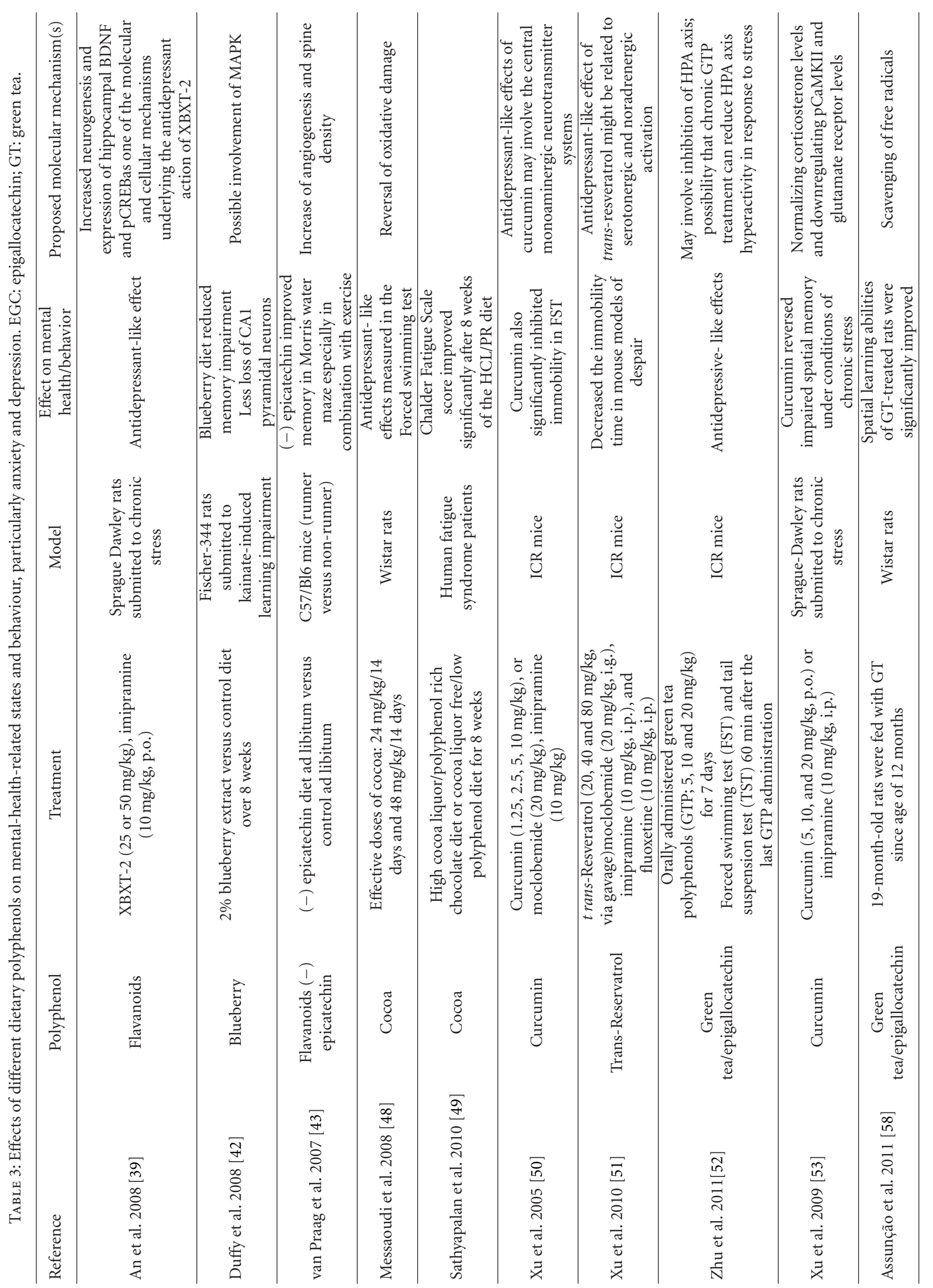




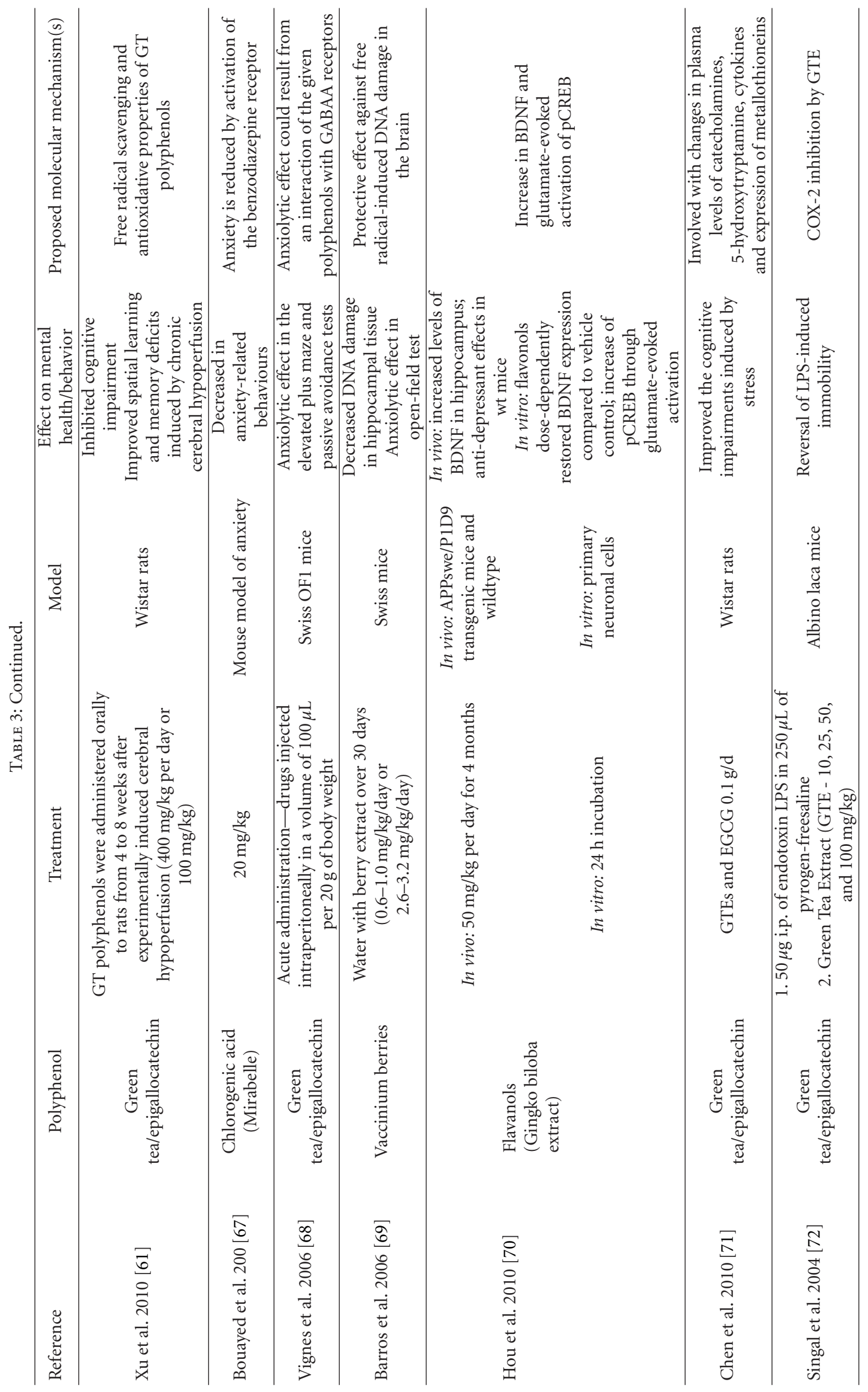




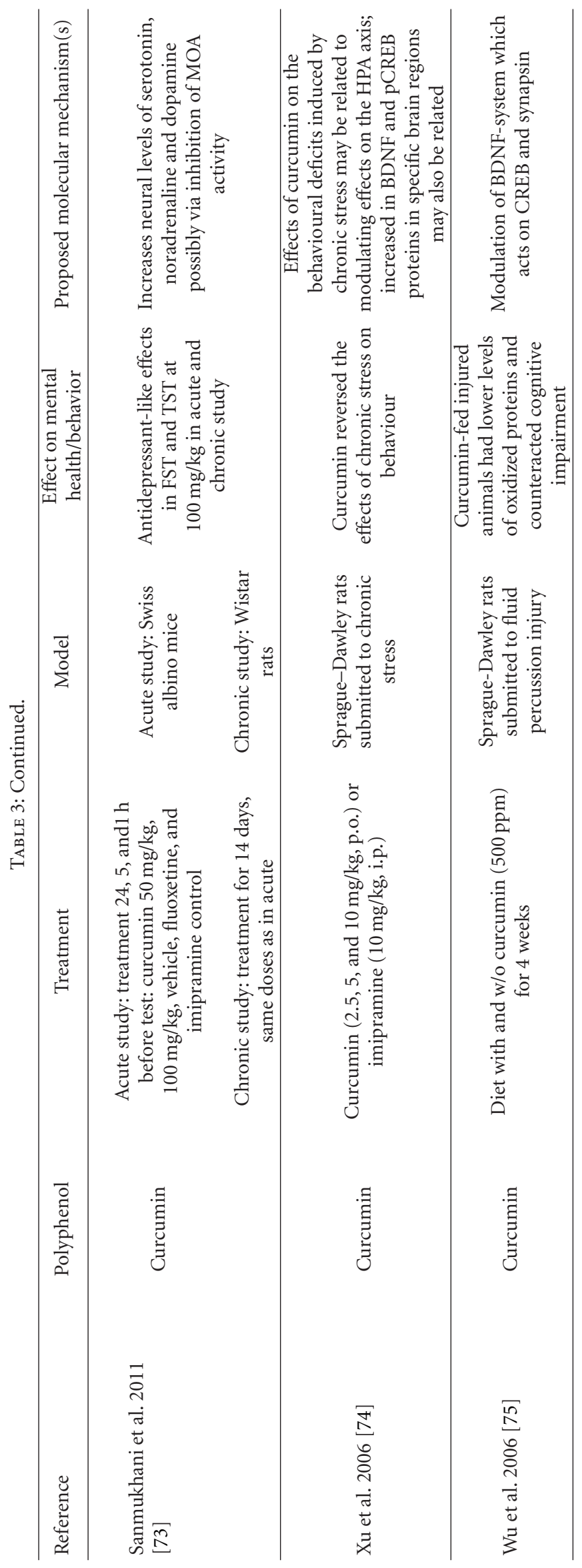


properties mediated through inhibition of the expression of inflammatory cytokines interleukin- $1 \beta$ (IL- $1 \beta$ ) and tumour necrosis factor- $\alpha$ (TNF- $\alpha$ ), inhibition of activities of the transcription factor nuclear factor- $\kappa \beta(\mathrm{NF}-\kappa \beta)$, and increased expression of the neurotrophic factor IGF-1 which may increase neural plasticity and neurogenesis [78]. Increases of these inflammatory cytokines and the transcription factor NF- $\kappa \beta$ have been associated with the development of mental health disorders and inhibition of these cytokines and NF- $\kappa \beta$ has been suggested as a method of treatment [79-82].

A number of polyphenols have been shown to have antidepressant-like effects as well. As was the case with polyphenols mediating anxiolytic effects, a variety of different mechanisms have been implicated for the antidepressant-like effects of different polyphenols. Ginkgobiloba extract contains many polyphenols including the flavonols quercetin, kaempferol, and isorhamnetin and has been shown to have antidepressant-like effects that could be due to its properties of increasing BDNF which would increase neuronal survival and plasticity or due its increase of pCREB through glutamate-invoked activation which would enhance synaptic strength and neuronal plasticity [70]. The ginkgo biloba flavonols quercetin and kaempferol also share the property of inhibiting the action of MOA's on serotonin and catecholamines with other polyphenols such as berry anthocyanins, the flavone apigenin in celery and the stilbene trans-resveratrol found in red wine [76, 77]. This MOA inhibition may contribute to antidepressant effects as elevated MOA activity is also linked to the etiology of depressive disorders [77]. The polyphenols in cocoa have also been shown to have antidepressant effects and to reduce the symptoms of chronic fatigue syndrome, possibly due to their anti-inflammatory properties mediated by inhibition of proinflammatory cytokines [48, 49, 83].

Green tea contains many polyphenols belonging to several molecular subclasses, including chlorogenic acid, pyrogallol, caffeic acid, (-)-epigallocatechin-3-gallate (EGCG), (-)-epigallocatechin (EGC), epicatechin-3-gallate (ECG), and (-)-epicatechin $[71,76,84]$. Green tea extracts have been shown to have antidepressant-like effects with multiple proposed mechanisms including antioxidant activity, regulation of adrenocorticotrophic hormone (ACTH) serum levels, inhibition of prostaglandins and inflammatory cytokines, increase of anti-inflammatory cytokines, and inhibition of MAO activity [52, 58, 71, 72, 85].

As can be seen in the examples of polyphenols discussed, many mechanisms of action for the antidepressant-like and anxiolytic behavioural effects of polyphenols show overlap between polyphenols and suggest shared cellular pathways that may interact and modulate each other.

A more detailed examination of a case in which the mechanisms of action for the antidepressant effects of the polyphenol have been elucidated may provide a clearer illustration of such modulation and interaction. The mechanisms of action for the polyphenol curcumin have been investigated in detail and provide an illustrative example of how polyphenol molecular and cellular pathways may interact with those established for conditions affecting neurogenesis and mental health such as stress and depression.
3.2. Proposed Curcumin Mechanisms of Antidepressant Action. The antidepressant effects of curcumin, a polyphenol which is the active ingredient in the spice turmeric, were investigated using the standard testing paradigms used to screen antidepressant drugs. The forced swimming test (FST) and tail suspension test (TST) are two standard animal models of depressive behaviour measurement in which the degree to which the animal ceases to struggle and becomes relatively passively immobile is used to assess depressive behaviour and both have been used as accurate methods for screening antidepressant properties of drugs when used in conjunction with locomotion-screening tests to distinguish any central nervous system stimulant properties [86, 87]. Curcumin was shown to dose-dependently reduce despair immobility behaviour in the TST and FST to a degree comparable to commonly prescribed tricyclic and selective serotonin re-uptake antidepressants [50, 73]. Further indepth behavioural comparisons combined with in vitro studies revealed that curcumin increased neural levels of serotonin, noradrenaline, and dopamine and inhibited MOA activity with molecular mechanisms that appear to differ from typical tricyclic and selective serotonin reuptake antidepressants $[50,73]$.

However, there were additional cellular mechanisms and antidepressant effects of curcumin revealed by a different animal model of depression which was based on prolonged stress and proved to be more sensitive to these diverse mechanisms. This stress model allowed a more detailed examination of curcumin's multiple mechanisms of action and reflected their complexity, illustrative of the diversity of mechanisms through which a single polyphenol can exert effect. Significantly, several of these pathways also act to upregulate neurogenesis, offering additional context for investigation of the cellular and molecular mechanisms by which other polyphenols exert antidepressant-like and anxiolytic effects.

Prolonged stress has been shown to have a role in the etiology of depression in humans and the chronic unpredictable stress in animal models of depression has been shown to parallel the anatomical, neuroendocrine, and behavioural aspects of depression in humans [74, 88, 89]. Thus the chronic unpredictable stress animal model has been productive in elucidating cellular and molecular mechanisms involved in the behavioural phenotype of depression and shown that antidepressant effects may be related in part to modulating the responses of the hypothalamus-pituitaryadrenal (HPA) axis [74, 89-92] (Figure 2).

Curcumin has been shown to have the ability to block or reverse the stress-induced changes typical of HPA axis dysfunction to a level comparable to a typical tricyclic antidepressant, including behavioural escape-response performance deficits, physiological changes in the adrenal gland, increases in corticosterone levels, reduced glucocorticoid receptor (GR) mRNA expression, decreased levels of BDNF, and reduced levels of phosphorylated CREB [74] (Figure 3).

Curcumin effects on restoring GR mRNA expression are particularly important when viewed in the context of HPA axis function. When functioning normally, activation of the HPA axis begins with the perception of physical or 


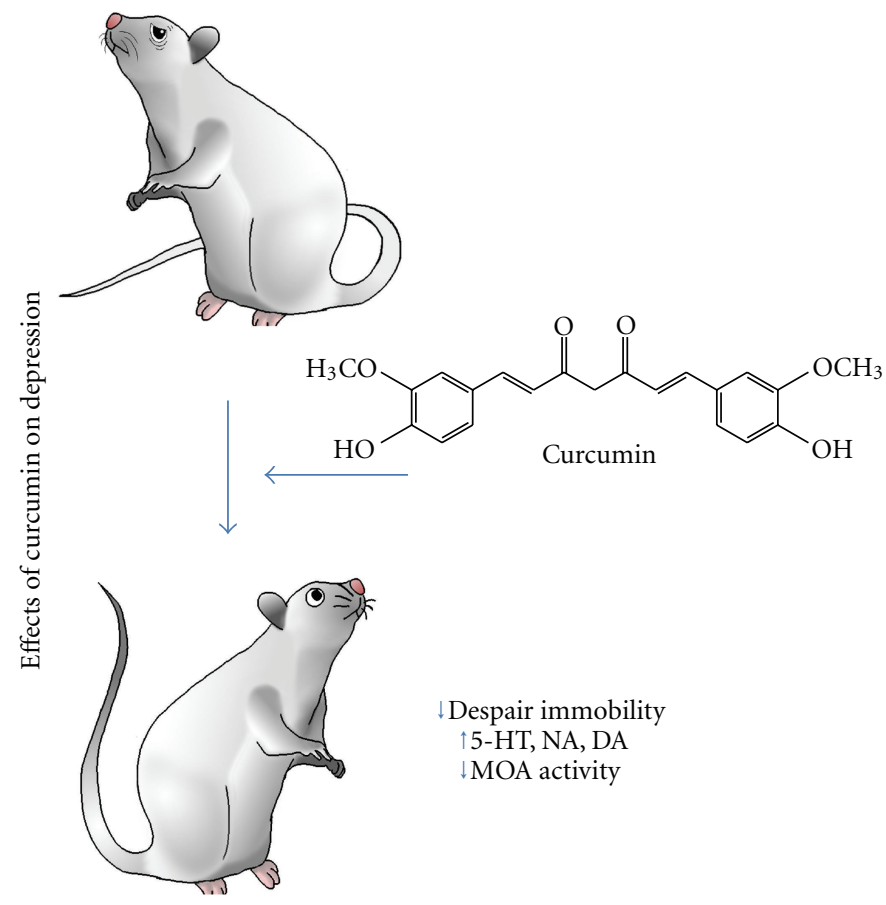

FIgURE 2: Effects of curcumin on depression. Administration of curcumin in rodent models of depression has been shown to ameliorate depressive-related behaviours, with decreased despair immobility, associated to increased levels of the neurotransmitters serotonin (5-HT), noradrenaline (NA), and dopamine (DA), and decreased activity of the enzyme monoamine oxidase (MOA).

psychological stress and results in stimulation of the adrenal cortex to release glucocorticoids (corticosterone in rodents and cortisol in humans). Glucocorticoids bind with the GR to regulate a number of systems in the body, including a self-limiting feedback mechanism acting to stop stimulation of glucocorticoid secretion and a GR feedback mechanism which lowers the production of inflammatory cytokines by inhibiting the activity of transcription factor NF- $\kappa \beta[93,94]$.

Thus glucocorticoids normally operate their own negative-feedback mechanism to stop HPA axis activation and to inhibit inflammation response; yet this negative feedback effect on both systems has been shown ineffective in depression where high levels of cortisol co-exist with high levels of proinflammatory cytokines [82, 95, 96]. This apparent lack of responsiveness to the feedback mechanism is called glucocorticoid resistance and is attributed to dysfunction of GR signalling rather than to elevated glucocorticoid levels [82, 94, 97, 98].

Curcumin's antidepressant-like effects in increasing levels of stress-reduced GR mRNA expression may be one of the keys in restoring normal levels of GR signalling for GR-modulated feedback mechanisms and, coupled with curcumin's increase of phosphorylated CREB, may also have implications for restoration of neurogenesis. A recent study has shown that antidepressants increase GR expression and induce GR nuclear translocation and transcription activities through pathways involving cyclic AMP and protein kinase
A (PKA) which cumulatively result in increased levels of neurogenesis [90]. This might elucidate the mechanism of antidepressant effects established by earlier works in which antidepressant drugs were shown to restore stressreduced levels of neurogenesis and GR expression, offering further context for understanding Curcumin's effects on GR expression [19, 29, 98].

Curcumin has also been shown to inhibit NF- $\kappa \beta$ activation pathways $[99,100]$. Activated NF- $\kappa \beta$ moves into the nucleus where it disrupts GR signalling, preventing proper functioning of GR feedback mechanisms [94, 97]. Activation of NF- $\kappa \beta$ also upregulates inflammatory cytokines which can have a number of effects also shown in the etiology of depression, including further dysregulation of the HPA axis, metabolism of monoamine neurotransmitters through elevated MOA activity, reduced neuronal plasticity, and reduced neurogenesis $[77,89,94]$. Therefore inhibition of NF- $\kappa \beta$ activation by curcumin has a number of antidepressantlike effects on the cellular level, preventing the reduced monoamine levels due to the elevated MOA activity, NF$\kappa \beta$ disruption of GR signalling, and the upregulation of inflammatory cytokines whose elevated levels would otherwise inhibit neurogenesis and further disrupt GR signalling $[89,90,101]$.

Curcumin administration in chronically stressed rats increased hippocampal neurogenesis via modulation of the HPA axis and upregulation of BDNF and 5-HT 1A 


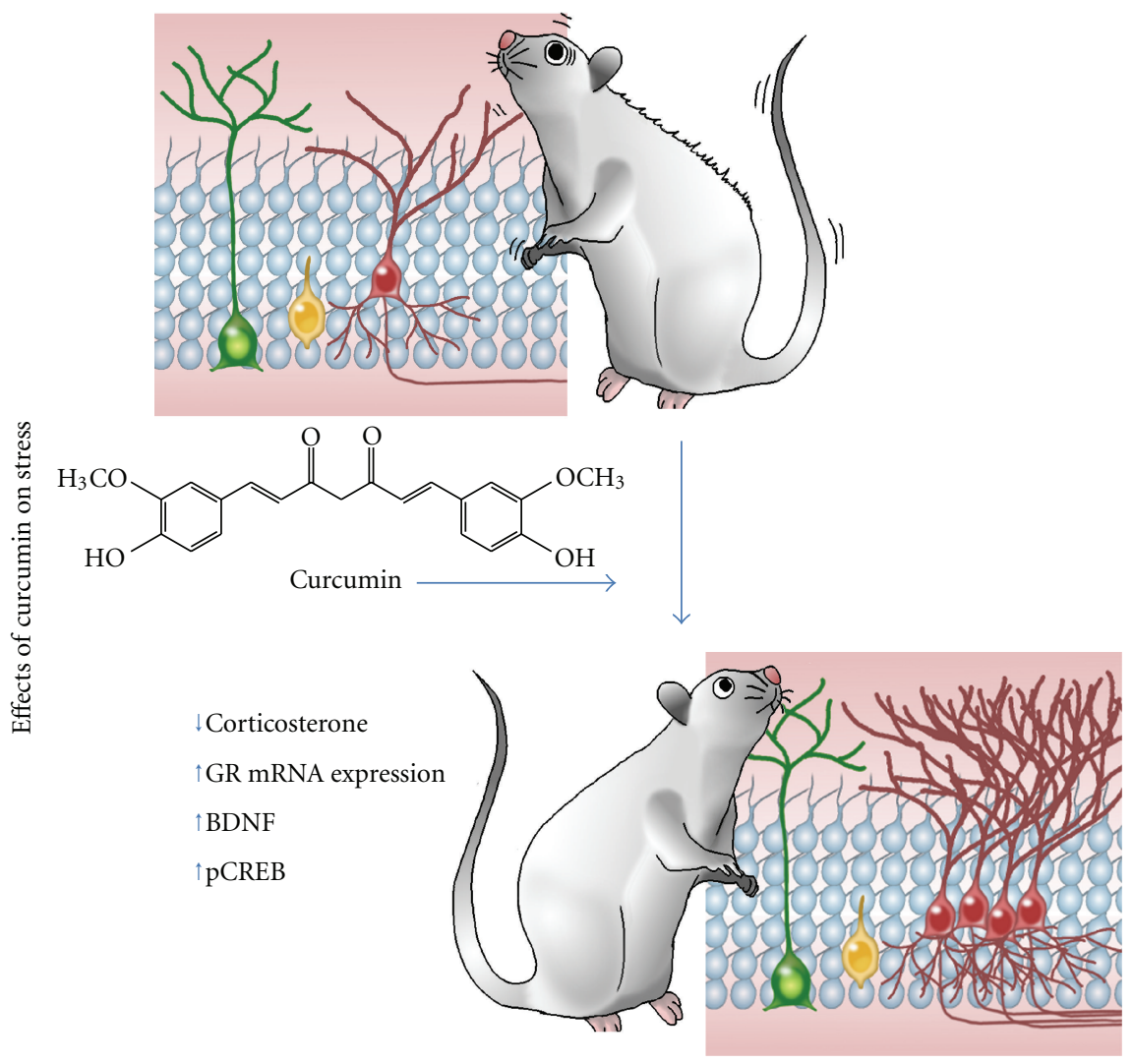

FIGURE 3: Effects of curcumin on stress. Administration of curcumin in rodent models of stress has been found to reduce stress-related behaviours, with decreased levels of the stress hormone corticosterone and increased levels of glucocorticoid receptor (GR) mRNA expression, brain-derived neurotrophic factor (BDNF), and phosphorilated cyclic AMP-response element DNA-binding protein (pCREB). Additionally, the decrease in AHN observed after exposure to stress has been found to be reversed following administration of curcumin.

receptors in the hippocampus [40]. Curcumin effects in restoring BDNF protein levels is important in the context of BDNF signalling in adult neurogenesis, shown to increase neuronal differentiation, survival, and dendritic arborisation $[29,102,103]$.

However, modulation of serotoninergic signalling has proven fundamental to curcumin antidepressant and neurogenic effects. The antidepressant-like effects of curcumin are mediated in part through direct agonistic functions on 5-HT $1 \mathrm{~A}$ and 5-HT $1 \mathrm{~B}$ receptors and antagonistic effects on 5-HT $2 \mathrm{C}$ receptors [104]. The effects mediated by curcumin upregulation of 5-HT 1A receptors may be even more critical to neurogenesis as 5 -HT 1A, 5 -HT $1 \mathrm{~B}$, and 5-HT 2A receptors have been proven necessary for adult hippocampal neurogenesis and 5-HT 1A receptor antagonists significantly decrease cell proliferation in the hippocampus $[105,106]$. The increased serotonin signalling resulting from upregulation of 5-HT 1A receptors and agonist effects on 5-HT 1A and 5$\mathrm{HT} 1 \mathrm{~B}$ receptors is also very pertinent to the antidepressant effects of curcumin as increased serotonin transmission has profound antidepressant effects as well as being associated with an increase in adult neurogenesis [105].

The effect of curcumin on 5-HT receptors also modulates GR signalling through serotonergic signalling activation of PKA. Activated PKA translocates to the nucleus where it can undergo protein-protein interactions with GR that optimise GR-DNA binding, stimulating GR signalling [94, 107]. In further interpathway modulation, activated PKA can also inhibit NF- $\kappa \beta$ from interfering with GR-DNA binding, thus increasing GR transcription activity through modulation of an additional pathway $[94,108]$.

Using the chronic unpredictable stress animal model of depression in combination with in vitro studies has provided details on many of the mechanisms through which curcumin exerted the antidepressant-like behavioural effects shown in FST and TST studies. As has been the case with many polyphenols, curcumin was shown to have multiple mechanisms of action that affect different cellular and molecular pathways, many of which have been shown to interact and modulate one another. Several of these pathways also act to upregulate neurogenesis both directly and indirectly, which is a further way in which curcumin may exert its antidepressant-like effects as some antidepressant drugs have been shown to exert neurogenesis-dependent behavioural effects $[30,109,110]$.

\section{Conclusion}

Given the high prevalence of depression and anxiety in modern societies, unravelling the neurobiological basis of 
these psychiatric conditions is one of the most challenging pursuits of science in the present days. The development of effective treatments for depression is likely to emerge from the identification of the mechanisms underlying its pathophysiological components [111]. In this context, studies on the effects of dietary polyphenols and elucidation of the mechanisms by which they exert these effects may play an important role as promising interventions in the field of mental health.

The present work discussed some recent findings addressing the effects of different dietary polyphenols on models of anxiety and depression and proposed mechanisms underlying these effects with particular focus on those related to AHN. As a whole, there is growing evidence for a positive effect of these plant- and food-derived components on behaviours related to depression and anxiety. The dietary polyphenols tested so far, however, appear to exert their effects through different and specific molecular pathways $[112,113]$, suggesting that the action of polyphenols is not uniform but highly specific. In addition, it should be noted that generalizing the effects of polyphenols as positive is still nonconsensual. For instance, on the one hand, the administration of 5,7,3' -trihydroxy-3,4-dimethoxyflavone (a flavonoid similar to kaempferol) led to significantly inhibited neurite outgrowth, and on the other hand, the polyphenol chlorogenic acid stimulated it [66].

Indeed, polyphenols are a very heterogenous group of natural chemical compounds that significantly differ with regard to their chemical properties. Studies have shown that the degree of polymerization and inherent properties such as molecular polarity can determine their potency in a range of actions, including antioxidation and antiinflammation $[83,114]$. These properties also affect the polyphenol level in different tissues, including the brain [36]. This diversity may explain why the same dietary source containing multiple polyphenols may show multiple effects as the effects of a single polyphenol may be either additive or altered when acting in the presence of other polyphenols $[76,78]$. This synergistic effect should be considered in future investigations aiming to find effective interventions in the field of mental health.

Some polyphenols have been shown to influence anxietyand depressive-like behaviours as well as AHN in different in vivo and in vitro models. However, further studies are necessary to clarify the potential of polyphenols in treating depression and anxiety. It is worth noting that a significant portion of the studies focusing on the effects of polyphenols on the hippocampus did not address AHN and used learning and memory paradigms as primarily models for studying neurodegenerative disorders like Alzheimer's disease. Given that AHN represents one of the most remarkable features of the central nervous system in terms of plasticity, more studies investigating the effects and mechanisms of polyphenols on hippocampal cell proliferation and differentiation may identify additional specific neurobiological targets for psychiatric-related behaviours. In addition, AHN has also been shown to correlate with anxiety [115-118] as well as emotional-and not only cognitive-learning and memory processes [119-121]. Also, it is clear that anxiety disorders present an important emotional mnemonic component [122]. Given the role of AHN in emotional learning and memory, future investigations that consider the potential effects of dietary polyphenols on depression and anxiety could expand our current understanding of these psychiatric conditions and provide evidence of their potential as tools for effective intervention.

\section{Key Messages}

(i) The adult hippocampus is capable of generating new neurons, but how these newly generated cells affect mental health and the different factors that can regulate AHN are still debated.

(ii) Polyphenol effects and bioavailability vary greatly due to their differing chemical, physical, and structural properties.

(iii) Plant-or food-derived polyphenols are widely known for their biological properties in enhancing cognition and neuroprotection in models of neurogenerative conditions, but some polyphenols can also increase cell proliferation and differentiation in models of anxiety and depression.

(iv) Different polyphenols exert their effects on AHN via different mechanisms of action, such as by activating the MAP kinase pathway or stimulating the expression and release of neurotrophic factors.

(v) Dietary polyphenols have been shown to affect mental health, having anxiolytic effects comparable to anxiolytic benzodiazepine drug chlordiazepoxide and antidepressant-like effects comparable to those of the SSRI antidepressant fluoxetine and TCA imipramine.

(vi) The anxiolytic and antidepressant-like effects of polyphenols are mediated through multiple molecular and cellular pathways, which interact and modulate one another.

\section{Authors' Contribution}

Nicole Cavegn and Alina Nix contributed equally to this work.

\section{Conflict of Interests}

The authors have no other relevant affiliations or financial involvement with any organization or entity with a financial interest in, or financial conflict with, the subject matter or materials discussed in the paper, apart from those disclosed. No writing assistance was utilized in the production of this paper.

\section{Acknowledgments}

The authors are thankful for the grants provided by The Research Councils UK, The Medical Research Council, The Psychiatry Research Trust, The Welton Foundation, The 
Brazilian Council for Scientific and Technological Development (CNPq), FAPERJ/PRONEX, INCT/CNPq/ National Institute of Translational Medicine, and INCT/CNPq/ National Institute of Translational Neuroscience, for this paper.

\section{References}

[1] P. S. Eriksson, E. Perfilieva, T. Björk-Eriksson et al., "Neurogenesis in the adult human hippocampus," Nature Medicine, vol. 4, no. 11, pp. 1313-1317, 1998.

[2] J. Altman, "Are new neurons formed in the brains of adult mammals?" Science, vol. 135, no. 3509, pp. 1127-1128, 1962.

[3] I. Imayoshi, M. Sakamoto, T. Ohtsuka et al., "Roles of continuous neurogenesis in the structural and functional integrity of the adult forebrain," Nature Neuroscience, vol. 11, no. 10, pp. 1153-1161, 2008.

[4] C. Zhao, W. Deng, and F. H. Gage, "Mechanisms and functional implications of adult neurogenesis," Cell, vol. 132, no. 4, pp. 645-660, 2008.

[5] G. L. Ming and H. Song, "Adult neurogenesis in the mammalian central nervous system," Annual Review of Neuroscience, vol. 28, pp. 223-250, 2005.

[6] J. Altman and G. D. Das, "Autoradiographic and histological studies of postnatal neurogenesis. I. A longitudinal investigation of the kinetics, migration and transformation of cells incorporating tritiated thymidine in neonate rats, with special reference to postnatal neurogenesis in some brain regions," Journal of Comparative Neurology, vol. 126, no. 3, pp. 337-389, 1966.

[7] E. Gould and P. Tanapat, "Lesion-induced proliferation of neuronal progenitors in the dentate gyrus of the adult rat," Neuroscience, vol. 80, no. 2, pp. 427-436, 1997.

[8] E. Gould, P. Tanapat, B. S. Mcewen, G. Flügge, and E. Fuchs, "Proliferation of granule cell precursors in the dentate gyrus of adult monkeys is diminished by stress," Proceedings of the National Academy of Sciences of the United States of America, vol. 95, no. 6, pp. 3168-3171, 1998.

[9] E. Gould, A. J. Reeves, M. S. A. Graziano, and C. G. Gross, "Neurogenesis in the neocortex of adult primates," Science, vol. 286, no. 5439, pp. 548-552, 1999.

[10] M. S. Kaplan and J. W. Hinds, "Neurogenesis in the adult rat: electron microscopic analysis of light radioautographs," Science, vol. 197, no. 4308, pp. 1092-1094, 1977.

[11] L. A. M. Galea and B. S. McEwen, "Sex and seasonal differences in the rate of cell proliferation in the dentate gyrus of adult wild meadow voles," Neuroscience, vol. 89, no. 3, pp. 955-964, 1999.

[12] D. R. Kornack and P. Rakic, "Continuation of neurogenesis in the hippocampus of the adult macaque monkey," Proceedings of the National Academy of Sciences of the United States of America, vol. 96, no. 10, pp. 5768-5773, 1999.

[13] A. Alvarez-Buylla and D. A. Lim, "For the long run: maintaining germinal niches in the adult brain," Neuron, vol. 41, no. 5, pp. 683-686, 2004.

[14] T. D. Palmer, A. R. Willhoite, and F. H. Gage, "Vascular niche for adult hippocampal neurogenesis," Journal of Comparative Neurology, vol. 425, no. 4, pp. 479-494, 2000.

[15] H. Van Praag, G. Kempermann, and F. H. Gage, "Running increases cell proliferation and neurogenesis in the adult mouse dentate gyrus," Nature Neuroscience, vol. 2, no. 3, pp. 266-270, 1999.
[16] G. Kempermann, H. G. Kuhn, and F. H. Gage, "More hippocampal neurons in adult mice living in an enriched environment," Nature, vol. 386, no. 6624, pp. 493-495, 1997.

[17] J. Lee, K. B. Seroogy, and M. P. Mattson, "Dietary restriction enhances neurotrophin expression and neurogenesis in the hippocampus of adult mice," Journal of Neurochemistry, vol. 80, no. 3, pp. 539-547, 2002.

[18] E. Gould and P. Tanapat, "Stress and hippocampal neurogenesis," Biological Psychiatry, vol. 46, no. 11, pp. 1472-1479, 1999.

[19] C. Mirescu and E. Gould, "Stress and adult neurogenesis," Hippocampus, vol. 16, no. 3, pp. 233-238, 2006.

[20] P. Tanapat, N. B. Hastings, T. A. Rydel, L. A. M. Galea, and E. Gould, "Exposure to fox odor inhibits cell proliferation in the hippocampus of adult rats via an adrenal hormonedependent mechanism," Journal of Comparative Neurology, vol. 437, no. 4, pp. 496-504, 2001.

[21] E. Gould, B. S. McEwen, P. Tanapat, L. A. M. Galea, and E. Fuchs, "Neurogenesis in the dentate gyrus of the adult tree shrew is regulated by psychosocial stress and NMDA receptor activation," Journal of Neuroscience, vol. 17, no. 7, pp. 24922498, 1997.

[22] J. E. Malberg and R. S. Duman, "Cell proliferation in adult hippocampus is decreased by inescapable stress: reversal by fluoxetine treatment," Neuropsychopharmacology, vol. 28, no. 9, pp. 1562-1571, 2003.

[23] D. T. Balu and I. Lucki, "Adult hippocampal neurogenesis: regulation, functional implications, and contribution to disease pathology," Neuroscience and Biobehavioral Reviews, vol. 33, no. 3, pp. 232-252, 2009.

[24] R. Jankord and J. P. Herman, "Limbic regulation of hypothalamo-pituitary-adrenocortical function during acute and chronic stress," Annals of the New York Academy of Sciences, vol. 1148, pp. 64-73, 2008.

[25] B. S. McEwen and T. Seeman, "Protective and damaging effects of mediators of stress. Elaborating and testing the concepts of allostasis and allostatic load," Annals of the New York Academy of Sciences, vol. 896, pp. 30-47, 1999.

[26] J. S. Snyder, A. Soumier, M. Brewer, J. Pickel, and H. A. Cameron, "Adult hippocampal neurogenesis buffers stress responses and depressive behaviour," Nature, vol. 476, no. 7361, pp. 458-461, 2011.

[27] S. Campbell, M. Marriott, C. Nahmias, and G. M. MacQueen, "Lower hippocampal volume in patients suffering from depression: a meta-analysis," American Journal of Psychiatry, vol. 161, no. 4, pp. 598-607, 2004.

[28] A. Dranovsky and R. Hen, "Hippocampal neurogenesis: regulation by stress and antidepressants," Biological Psychiatry, vol. 59, no. 12, pp. 1136-1143, 2006.

[29] J. E. Malberg, A. J. Eisch, E. J. Nestler, and R. S. Duman, "Chronic antidepressant treatment increases neurogenesis in adult rat hippocampus," Journal of Neuroscience, vol. 20, no. 24, pp. 9104-9110, 2000.

[30] L. Santarelli, M. Saxe, C. Gross et al., "Requirement of hippocampal neurogenesis for the behavioral effects of antidepressants," Science, vol. 301, no. 5634, pp. 805-809, 2003.

[31] A. Marín-Burgin and A. F. Schinder, "Requirement of adult-born neurons for hippocampus-dependent learning," Behavioural Brain Research, vol. 227, no. 2, pp. 391-399, 2011.

[32] B. Vollmayr, C. Simonis, S. Weber, P. Gass, and F. Henn, "Reduced cell proliferation in the dentate gyrus is not 
correlated with the development of learned helplessness," Biological Psychiatry, vol. 54, no. 10, pp. 1035-1040, 2003.

[33] A. Surget, M. Saxe, S. Leman et al., "Drug-dependent requirement of hippocampal neurogenesis in a model of depression and of antidepressant reversal," Biological Psychiatry, vol. 64, no. 4, pp. 293-301, 2008.

[34] D. Stangl and S. Thuret, "Impact of diet on adult hippocampal neurogenesis," Genes and Nutrition, vol. 4, no. 4, pp. 271282, 2009.

[35] F. Gómez-Pinilla, "Brain foods: the effects of nutrients on brain function," Nature Reviews Neuroscience, vol. 9, no. 7, pp. 568-578, 2008.

[36] J. P. E. Spencer, "Food for thought: the role of dietary flavonoids in enhancing human memory, learning and neuro-cognitive performance," Proceedings of the Nutrition Society, vol. 67, no. 2, pp. 238-252, 2008.

[37] T. Valente, J. Hidalgo, I. Bolea et al., "A diet enriched in polyphenols and polyunsaturated fatty acids, LMN diet, induces neurogenesis in the subventricular zone and hippocampus of adult mouse brain," Journal of Alzheimer's Disease, vol. 18, no. 4, pp. 849-865, 2009.

[38] J. K. So, G. S. Tae, R. P. Hee et al., "Curcumin stimulates proliferation of embryonic neural progenitor cells and neurogenesis in the adult hippocampus," The Journal of Biological Chemistry, vol. 283, no. 21, pp. 14497-14505, 2008.

[39] L. An, Y. Z. Zhang, N. J. Yu et al., "The total flavonoids extracted from Xiaobuxin-Tang up-regulate the decreased hippocampal neurogenesis and neurotrophic molecules expression in chronically stressed rats," Progress in NeuroPsychopharmacology and Biological Psychiatry, vol. 32, no. 6, pp. 1484-1490, 2008.

[40] Y. Xu, B. Ku, L. Cui et al., "Curcumin reverses impaired hippocampal neurogenesis and increases serotonin receptor $1 \mathrm{~A}$ mRNA and brain-derived neurotrophic factor expression in chronically stressed rats," Brain Research, vol. 1162, no. 1, pp. 9-18, 2007.

[41] T. Wang, Y. J. Yang, P. F. Wu et al., "Tetrahydroxystilbene glucoside, a plant-derived cognitive enhancer, promotes hippocampal synaptic plasticity," European Journal of Pharmacology, vol. 650, no. 1, pp. 206-214, 2011.

[42] K. B. Duffy, E. L. Spangler, B. D. Devan et al., "A blueberryenriched diet provides cellular protection against oxidative stress and reduces a kainate-induced learning impairment in rats," Neurobiology of Aging, vol. 29, no. 11, pp. 1680-1689, 2008.

[43] H. Van Praag, M. J. Lucero, G. W. Yeo et al., "Plant-derived flavanol (-)epicatechin enhances angiogenesis and retention of spatial memory in mice," Journal of Neuroscience, vol. 27, no. 22, pp. 5869-5878, 2007.

[44] S. A. Mandel, T. Amit, O. Weinreb, and M. B. H. Youdim, "Understanding the broad-spectrum neuroprotective action profile of green tea polyphenols in aging and neurodegenerative diseases," Journal of Alzheimer's Disease, vol. 25, no. 2, pp. 187-208, 2011.

[45] L. Rossi, S. Mazzitelli, M. Arciello, C. R. Capo, and G. Rotilio, "Benefits from dietary polyphenols for brain aging and Alzheimer's disease," Neurochemical Research, vol. 33, no. 12, pp. 2390-2400, 2008.

[46] B. L. Queen and T. O. Tollefsbol, "Polyphenols and aging," Current Aging Science, vol. 3, no. 1, pp. 34-42, 2010.

[47] D.-Y. Choi, Y.-J. Lee, J. T. Hong, and H.-J. Lee, "Antioxidant properties of natural polyphenols and their therapeutic potentials for Alzheimer's disease," Brain Research Bulletin, vol. 87, no. 2-3, pp. 144-153, 2012.
[48] M. Messaoudi, J. F. Bisson, A. Nejdi, P. Rozan, and H. Javelot, "Antidepressant-like effects of a cocoa polyphenolic extract in Wistar-Unilever rats," Nutritional Neuroscience, vol. 11, no. 6, pp. 269-276, 2008.

[49] T. Sathyapalan, S. Beckett, A. S. Rigby, D. D. Mellor, and S. L. Atkin, "High cocoa polyphenol rich chocolate may reduce the burden of the symptoms in chronic fatigue syndrome," Nutrition Journal, vol. 9, no. 1, article 55, 2010.

[50] Y. Xu, B. S. Ku, H. Y. Yao et al., "The effects of curcumin on depressive-like behaviors in mice," European Journal of Pharmacology, vol. 518, no. 1, pp. 40-46, 2005.

[51] Y. Xu, Z. Wang, W. You et al., "Antidepressant-like effect of trans-resveratrol: involvement of serotonin and noradrenaline system," European Neuropsychopharmacology, vol. 20, no. 6, pp. 405-413, 2010.

[52] W.-L. Zhu, H.-S. Shi, Y.-M. Wei et al., "Green tea polyphenols produce antidepressant-like effects in adult mice," Pharmacological Research, vol. 65, no. 1, pp. 74-80, 2012.

[53] Y. Xu, D. Lin, S. Li et al., "Curcumin reverses impaired cognition and neuronal plasticity induced by chronic stress," Neuropharmacology, vol. 57, no. 4, pp. 463-471, 2009.

[54] L. Fernández-Fernández, G. Comes, I. Bolea et al., "LMN diet, rich in polyphenols and polyunsaturated fatty acids, improves mouse cognitive decline associated with aging and Alzheimer's disease," Behavioural Brain Research, vol. 228, no. 2, pp. 261-271, 2012.

[55] J. A. Joseph, B. Shukitt-Hale, G. J. Brewer, K. A. Weikel, W. Kalt, and D. R. Fisher, "Differential protection among fractionated blueberry polyphenolic families against DA-, $\mathrm{A} \beta_{42}$ - and LPS-Induced decrements in $\mathrm{Ca}^{2+}$ buffering in primary hippocampal cells," Journal of Agricultural and Food Chemistry, vol. 58, no. 14, pp. 8196-8204, 2010.

[56] K. Narita, M. Hisamoto, T. Okuda, and S. Takeda, "Differential neuroprotective activity of two different grape seed extracts," PLoS ONE, vol. 6, no. 1, Article ID e14575, 2011.

[57] K. Fujishita, T. Ozawa, K. Shibata et al., "Grape seed extract acting on astrocytes reveals neuronal protection against oxidative stress via interleukin-6-mediated mechanisms," Cellular and Molecular Neurobiology, vol. 29, no. 8, pp. 11211129, 2009.

[58] M. Assunção, M. J. Santos-Marques, F. Carvalho, N. V. Lukoyanov, and J. P. Andrade, "Chronic green tea consumption prevents age-related changes in rat hippocampal formation," Neurobiology of Aging, vol. 32, no. 4, pp. 707-717, 2011.

[59] M. Assunção, M. J. Santos-Marques, F. Carvalho, and J. P. Andrade, "Green tea averts age-dependent decline of hippocampal signaling systems related to antioxidant defenses and survival," Free Radical Biology and Medicine, vol. 48, no. 6, pp. 831-838, 2010.

[60] S. T. Yin, M. L. Tang, L. Su et al., "Effects of Epigallocatechin3-gallate on lead-induced oxidative damage," Toxicology, vol. 249, no. 1, pp. 45-54, 2008.

[61] Y. Xu, J. J. Zhang, L. Xiong, L. Zhang, D. Sun, and H. Liu, "Green tea polyphenols inhibit cognitive impairment induced by chronic cerebral hypoperfusion via modulating oxidative stress," Journal of Nutritional Biochemistry, vol. 21, no. 8, pp. 741-748, 2010.

[62] G. Casadesus, B. Shukitt-Hale, H. M. Stellwagen et al., "Modulation of hippocampal plasticity and cognitive behavior by short-term blueberry supplementation in aged rats," Nutritional Neuroscience, vol. 7, no. 5-6, pp. 309-316, 2004. 
[63] A. Scalbert and G. Williamson, "Dietary intake and bioavailability of polyphenols," Journal of Nutrition, vol. 130, no. 8, 2000.

[64] J. P. E. Spencer, K. Vafeiadou, R. J. Williams, and D. Vauzour, "Neuroinflammation: modulation by flavonoids and mechanisms of action," Molecular Aspects of Medicine, vol. 33, no. 1, pp. 83-97, 2012.

[65] S. Acosta, J. Jernberg, C. D. Sanberg et al., "NT-020, a natural therapeutic approach to optimize spatial memory performance and increase neural progenitor cell proliferation and decrease inflammation in the aged rat," Rejuvenation Research, vol. 13, no. 5, pp. 581-588, 2010.

[66] H. Ito, X. L. Sun, M. Watanabe, M. Okamoto, and T. Hatano, "Chlorogenic acid and its metabolite m-coumaric acid evoke neurite outgrowth in hippocampal neuronal cells," Bioscience, Biotechnology and Biochemistry, vol. 72, no. 3, pp. 885-888, 2008.

[67] J. Bouayed, H. Rammal, A. Dicko, C. Younos, and R. Soulimani, "Chlorogenic acid, a polyphenol from Prunus domestica (Mirabelle), with coupled anxiolytic and antioxidant effects," Journal of the Neurological Sciences, vol. 262, no. 1-2, pp. 77-84, 2007.

[68] M. Vignes, T. Maurice, F. Lanté et al., "Anxiolytic properties of green tea polyphenol (-)-epigallocatechin gallate (EGCG)," Brain Research, vol. 1110, no. 1, pp. 102-115, 2006.

[69] D. Barros, O. B. Amaral, I. Izquierdo et al., "Behavioral and genoprotective effects of Vaccinium berries intake in mice," Pharmacology Biochemistry and Behavior, vol. 84, no. 2, pp. 229-234, 2006.

[70] Y. Hou, M. A. Aboukhatwa, D. L. Lei, K. Manaye, I. Khan, and Y. Luo, "Anti-depressant natural flavonols modulate BDNF and beta amyloid in neurons and hippocampus of double TgAD mice," Neuropharmacology, vol. 58, no. 6, pp. 911-920, 2010.

[71] W. Q. Chen, X. L. Zhao, D. L. Wang et al., "Effects of epigallocatechin-3-gallate on behavioral impairments induced by psychological stress in rats," Experimental Biology and Medicine, vol. 235, no. 5, pp. 577-583, 2010.

[72] A. Singal, N. Tirkey, and K. Chopra, "Reversal of LPSinduced immobility in mice by green tea polyphenols: possible COX-2 mechanism," Phytotherapy Research, vol. 18, no. 9, pp. 723-728, 2004.

[73] J. Sanmukhani, A. Anovadiya, and C. B. Tripathi, "Evaluation of antidepressant like activity of curcumin and its combination with fluoxetine and imipramine: an acute and chronic study," Acta poloniae pharmaceutica, vol. 68, no. 5, pp. 769775, 2011.

[74] Y. Xu, B. Ku, L. Tie et al., "Curcumin reverses the effects of chronic stress on behavior, the HPA axis, BDNF expression and phosphorylation of CREB," Brain Research, vol. 1122, no. 1, pp. 56-64, 2006.

[75] A. Wu, Z. Ying, and F. Gomez-Pinilla, "Dietary curcumin counteracts the outcome of traumatic brain injury on oxidative stress, synaptic plasticity, and cognition," Experimental Neurology, vol. 197, no. 2, pp. 309-317, 2006.

[76] C. Manach, A. Scalbert, C. Morand, C. Rémésy, and L. Jiménez, "Polyphenols: food sources and bioavailability," American Journal of Clinical Nutrition, vol. 79, no. 5, pp. 727747, 2004.

[77] A. Dreiseitel, G. Korte, P. Schreier et al., "Berry anthocyanins and their aglycons inhibit monoamine oxidases A and B," Pharmacological Research, vol. 59, no. 5, pp. 306-311, 2009.

[78] B. Shukitt-Hale, F. C. Lau, A. N. Carey et al., "Blueberry polyphenols attenuate kainic acid-induced decrements in cognition and alter inflammatory gene expression in rat hippocampus," Nutritional Neuroscience, vol. 11, no. 4, pp. 172-182, 2008.

[79] R. Dantzer, "Cytokine, sickness behavior, and depression," Immunology and Allergy Clinics of North America, vol. 29, no. 2, pp. 247-264, 2009.

[80] J. K. Kiecolt-Glaser, "Stress, food, and inflammation: psychoneuroimmunology and nutrition at the cutting edge," Psychosomatic Medicine, vol. 72, no. 4, pp. 365-369, 2010.

[81] S. M. O’Brien, L. V. Scott, and T. G. Dinan, “Cytokines: abnormalities in major depression and implications for pharmacological treatment," Human Psychopharmacology, vol. 19, no. 6, pp. 397-403, 2004.

[82] C. L. Raison, L. Capuron, and A. H. Miller, "Cytokines sing the blues: inflammation and the pathogenesis of depression," Trends in Immunology, vol. 27, no. 1, pp. 24-31, 2006.

[83] T. Mao, J. Van De Water, C. L. Keen, H. H. Schmitz, and M. E. Gershwin, "Cocoa procyanidins and human cytokine transcription and secretion," Journal of Nutrition, vol. 130, no. 8, pp. 2093S-2099S, 2000.

[84] L. Ferrara, D. Montesano, and A. Senatore, "The distribution of minerals and flavonoids in the tea plant (Camellia sinensis)," Farmaco, vol. 56, no. 5-7, pp. 397-401, 2001.

[85] Q. Deng, J. Xu, B. Yu et al., "Effect of dietary tea polyphenols on growth performance and cell-mediated immune response of post-weaning piglets under oxidative stress," Archives of Animal Nutrition, vol. 64, no. 1, pp. 12-21, 2010.

[86] R. D. Porsolt, A. Bertin, and M. Jalfre, “'Behavioral despair' in rats and mice: strain differences and the effects of imipramine," European Journal of Pharmacology, vol. 51, no. 3, pp. 291-294, 1978.

[87] L. Steru, R. Chermat, B. Thierry, and P. Simon, "The tail suspension test: a new method for screening antidepressants in mice," Psychopharmacology, vol. 85, no. 3, pp. 367-370, 1985.

[88] B. E. Leonard, "The HPA and immune axes in stress: the involvement of the serotonergic system," European Psychiatry, vol. 20, supplement 3, pp. S302-S306, 2005.

[89] C. Song and H. Wang, "Cytokines mediated inflammation and decreased neurogenesis in animal models of depression," Progress in Neuro-Psychopharmacology and Biological Psychiatry, vol. 35, no. 3, pp. 760-768, 2011.

[90] C. Anacker, P. A. Zunszain, A. Cattaneo et al., "Antidepressants increase human hippocampal neurogenesis by activating the glucocorticoid receptor," Molecular Psychiatry, vol. 16, no. 7, pp. 738-750, 2011.

[91] N. Barden, J. M. H. M. Reul, and F. Holsboer, "Do antidepressants stabilize mood through actions on the hypothalamicpituitary-adrenocortical system?" Trends in Neurosciences, vol. 18, no. 1, pp. 6-11, 1995.

[92] R. Garcia, "Stress, metaplasticity, and antidepressants," Current Molecular Medicine, vol. 2, no. 7, pp. 629-638, 2002.

[93] F. A. Antoni, "Vasopressinergic control of pituitary adrenocorticotropin secretion comes of age," Frontiers in Neuroendocrinology, vol. 14, no. 2, pp. 76-122, 1993.

[94] T. W. W. Pace, F. Hu, and A. H. Miller, "Cytokine-effects on glucocorticoid receptor function: relevance to glucocorticoid resistance and the pathophysiology and treatment of major depression," Brain, Behavior, and Immunity, vol. 21, no. 1, pp. 9-19, 2007.

[95] E. E. L. Beckham, Handbook of Depression, Guilford Press, London, UK, 1995.

[96] M. Maes, S. Scharpe, H. Y. Meltzer et al., "Relationships between interleukin- 6 activity, acute phase proteins, and 
function of the hypothalamic-pituitary-adrenal axis in severe depression," Psychiatry Research, vol. 49, no. 1, pp. 11-27, 1993.

[97] A. H. Miller, C. M. Pariante, and B. D. Pearce, "Effects of cytokines on glucocorticoid receptor expression and function: glucocorticoid resistance and relevance to depression," Advances in Experimental Medicine and Biology, vol. 461, pp. 107-116, 1999.

[98] P. A. Zunszain, C. Anacker, A. Cattaneo, L. A. Carvalho, and C. M. Pariante, "Glucocorticoids, cytokines and brain abnormalities in depression," Progress in NeuroPsychopharmacology and Biological Psychiatry, vol. 35, no. 3, pp. 722-729, 2011.

[99] Y. G. Lin, A. B. Kunnumakkara, A. Nair et al., "Curcumin inhibits tumor growth and angiogenesis in ovarian carcinoma by targeting the nuclear factor- $\kappa \mathrm{B}$ pathway," Clinical Cancer Research, vol. 13, no. 11, pp. 3423-3430, 2007.

[100] S. Singh and B. B. Aggarwal, "Activation of transcription factor NF- $\kappa$ b is suppressed by curcumin (diferuloylmethane)," The Journal of Biological Chemistry, vol. 270, no. 50, p. 30235, 1995.

[101] L. I. McKay and J. A. Cidlowski, "Molecular control of immune/inflammatory responses: interactions between nuclear factor- $\kappa \mathrm{B}$ and steroid receptor-signaling pathways," Endocrine Reviews, vol. 20, no. 4, pp. 435-459, 1999.

[102] Y. Mu, S. W. Lee, and F. H. Gage, "Signaling in adult neurogenesis," Current Opinion in Neurobiology, vol. 20, no. 4, pp. 416-423, 2010.

[103] M. Nibuya, S. Morinobu, and R. S. Duman, "Regulation of BDNF and trkB mRNA in rat brain by chronic electroconvulsive seizure and antidepressant drug treatments," Journal of Neuroscience, vol. 15, no. 11, pp. 7539-7547, 1995.

[104] R. Wang, Y. Xu, H. L. Wu et al., "The antidepressant effects of curcumin in the forced swimming test involve 5-HT1 and 5HT2 receptors," European Journal of Pharmacology, vol. 578, no. 1, pp. 43-50, 2008.

[105] M. Banasr, M. Hery, R. Printemps, and A. Daszuta, "Serotonin-induced increases in adult cell proliferation and neurogenesis are mediated through different and common 5 -HT receptor subtypes in the dentate gyrus and the subventricular zone," Neuropsychopharmacology, vol. 29, no. 3, pp. 450-460, 2004.

[106] J. J. Radley and B. L. Jacobs, “5-HT1A receptor antagonist administration decreases cell proliferation in the dentate gyrus," Brain Research, vol. 955, no. 1-2, pp. 264-267, 2002.

[107] M. Saxena, S. Williams, K. Taskén, and T. Mustelin, "Crosstalk between cAMP-dependent kinase and MAP kinase through a protein tyrosine phosphatase," Nature Cell Biology, vol. 1, no. 5, pp. 305-311, 1999.

[108] N. Takahashi, T. Tetsuka, H. Uranishi, and T. Okamoto, "Inhibition of the NF- $\kappa \mathrm{B}$ transcriptional activity by protein kinase A," European Journal of Biochemistry, vol. 269, no. 18, pp. 4559-4565, 2002.

[109] D. J. David, J. Wang, B. A. Samuels et al., "Implications of the functional integration of adult-born hippocampal neurons in anxiety-depression disorders," Neuroscientist, vol. 16, no. 5, pp. 578-591, 2010.

[110] D. Petrik, D. C. Lagace, and A. J. Eisch, "The neurogenesis hypothesis of affective and anxiety disorders: are we mistaking the scaffolding for the building?" Neuropharmacology, vol. 62, no. 1, pp. 21-34, 2012.

[111] A. Sahay and R. Hen, "Adult hippocampal neurogenesis in depression," Nature Neuroscience, vol. 10, no. 9, pp. 1110$1115,2007$.
[112] J. P. E. Spencer, D. Vauzour, and C. Rendeiro, "Flavonoids and cognition: the molecular mechanisms underlying their behavioural effects," Archives of Biochemistry and Biophysics, vol. 492, no. 1-2, pp. 1-9, 2009.

[113] B. Shukitt-Hale, A. N. Carey, D. Jenkins, B. M. Rabin, and J. A. Joseph, "Beneficial effects of fruit extracts on neuronal function and behavior in a rodent model of accelerated aging," Neurobiology of Aging, vol. 28, no. 8, pp. 1187-1194, 2007.

[114] M. Miyake, K. Sasaki, K. Ide, Y. Matsukura, K. Shijima, and D. Fujiwara, "Highly oligomeric procyanidins ameliorate experimental autoimmune encephalomyelitis via suppression of Th1 immunity," Journal of Immunology, vol. 176, no. 10, pp. 5797-5804, 2006.

[115] H. Ageta, A. Murayama, R. Migishima et al., "Activin in the brain modulates anxiety-related behavior and adult neurogenesis," PLoS ONE, vol. 3, no. 4, Article ID e1869, 2008.

[116] M. Bergami, R. Rimondini, S. Santi, R. Blum, M. Götz, and M. Canossa, "Deletion of TrkB in adult progenitors alters newborn neuron integration into hippocampal circuits and increases anxiety-like behavior," Proceedings of the National Academy of Sciences of the United States of America, vol. 105, no. 40, pp. 15570-15575, 2008.

[117] J. L. Trejo, M. V. LLorens-Martín, and I. Torres-Alemán, "The effects of exercise on spatial learning and anxiety-like behavior are mediated by an IGF-I-dependent mechanism related to hippocampal neurogenesis," Molecular and Cellular Neuroscience, vol. 37, no. 2, pp. 402-411, 2008.

[118] J. N. Salam, J. H. Fox, E. M. DeTroy, M. H. Guignon, D. F. Wohl, and W. A. Falls, "Voluntary exercise in C57 mice is anxiolytic across several measures of anxiety," Behavioural Brain Research, vol. 197, no. 1, pp. 31-40, 2009.

[119] K. Pham, B. S. McEwen, J. E. Ledoux, and K. Nader, "Fear learning transiently impairs hippocampal cell proliferation," Neuroscience, vol. 130, no. 1, pp. 17-24, 2005.

[120] J. L. Warner-Schmidt, T. M. Madsen, and R. S. Duman, "Electroconvulsive seizure restores neurogenesis and hippocampus-dependent fear memory after disruption by irradiation," European Journal of Neuroscience, vol. 27, no. 6, pp. 1485-1493, 2008.

[121] M. D. Saxe, F. Battaglia, J. W. Wang et al., "Ablation of hippocampal neurogenesis impairs contextual fear conditioning and synaptic plasticity in the dentate gyrus," Proceedings of the National Academy of Sciences of the United States of America, vol. 103, no. 46, pp. 17501-17506, 2006.

[122] N. N. Karpova, A. Pickenhagen, J. Lindholm et al., "Fear erasure in mice requires synergy between antidepressant drugs and extinction training," Science, vol. 334, no. 6063, pp. 1731-1734, 2011. 


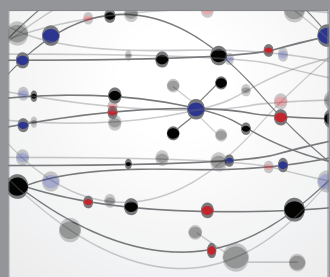

The Scientific World Journal
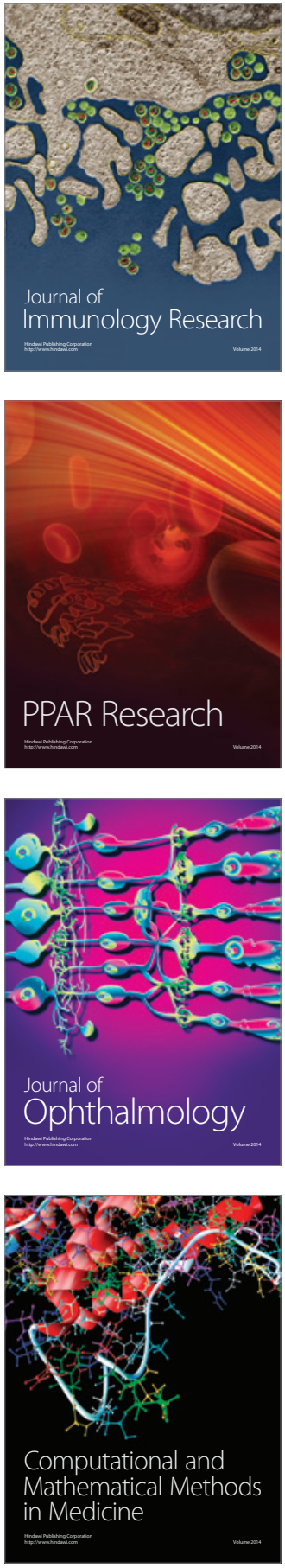

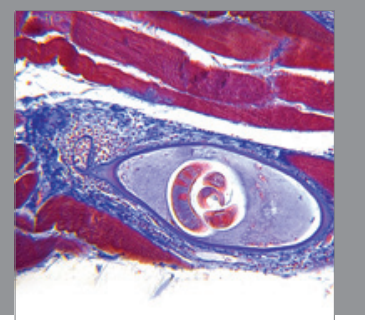

Gastroenterology

Research and Practice
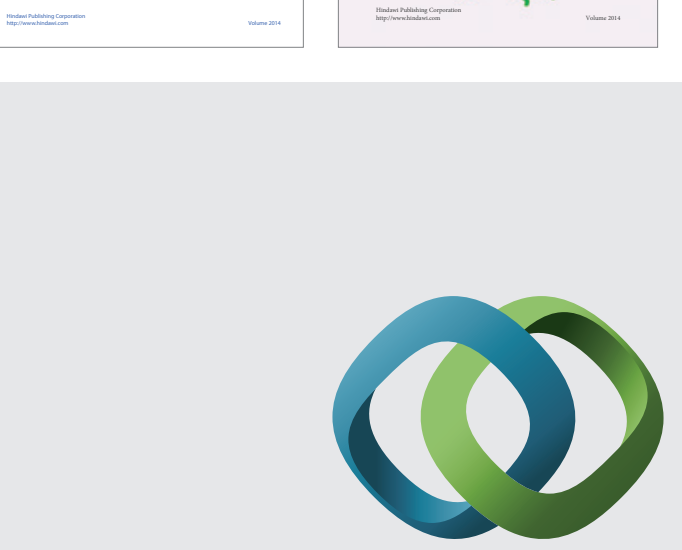

\section{Hindawi}

Submit your manuscripts at

http://www.hindawi.com
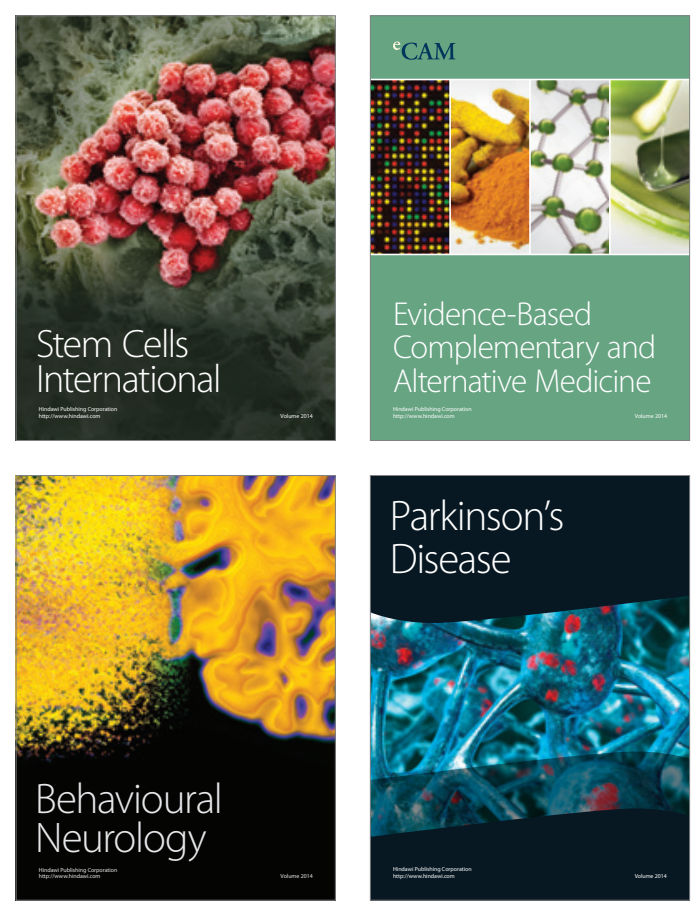

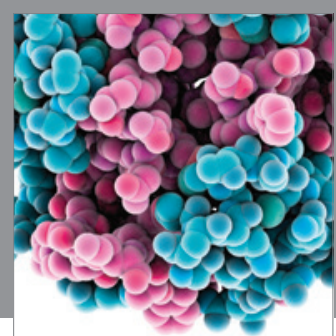

Journal of
Diabetes Research

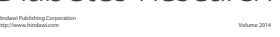

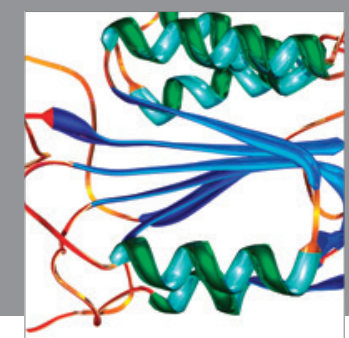

Disease Markers
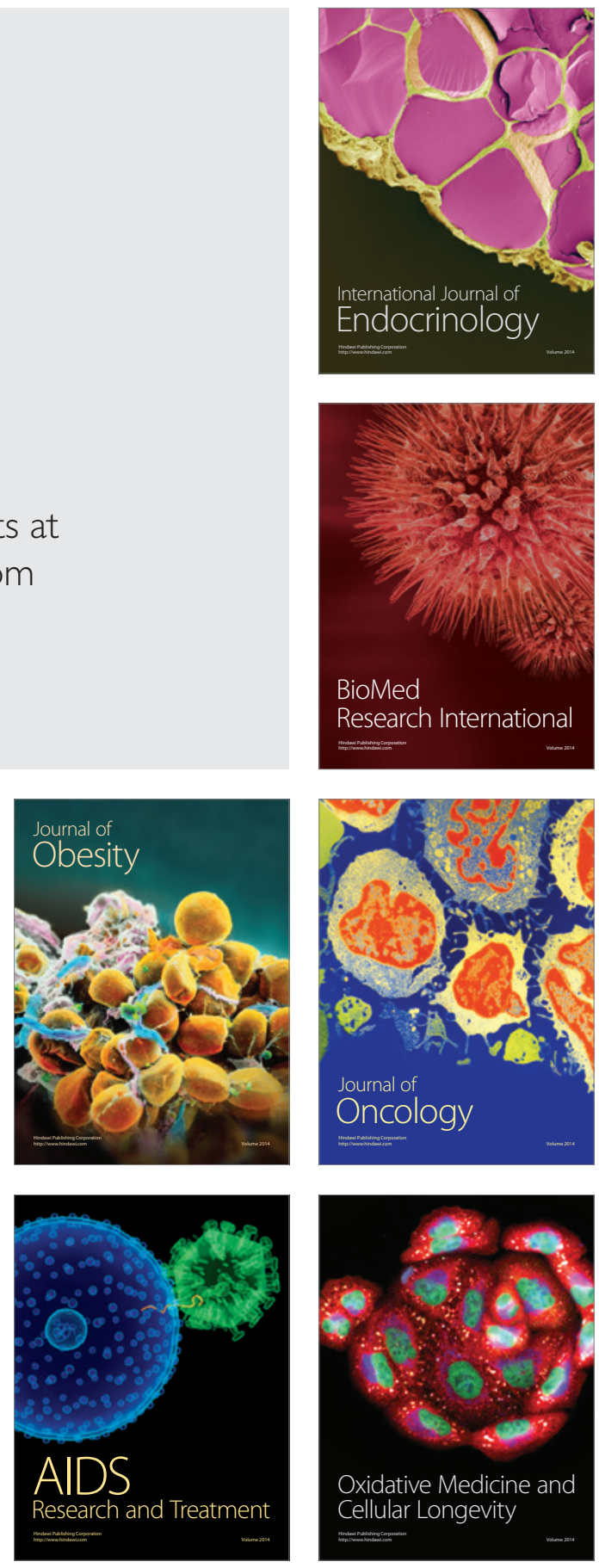